\title{
From the Ethics of Technology to the Ethics of Knowledge Assessment
}

\author{
René Von Schomberg ${ }^{1}$ \\ European Commission \\ Directorate General for Research \\ Rene.vonschomberg@ec.europa.eu
}

\begin{abstract}
This paper gives an overview of the way foresight knowledge concerning scientific and technological developments is deliberated in policy. It also offers an approach to assessing the quality of foresight knowledge generated during foresight exercises. Although "foresight knowledge" is a special case, the idea of having a procedure, approach or method available for assessing the quality of knowledge is tempting: foresight knowledge comes from various sources such as different scientific disciplines, normative visions on the future, planning, and scenario's. It also receives input from different sectors of society, such as industry, academia and civil society. How can we then assess the quality of knowledge inputs from such diverse sources and its implication for foresight exercises? This paper is a first attempt to address this subject matter. We realise that this type of work has not been done before, and we hope therefore that this first attempt will stimulate others to further explore this issue. Since the aim of this paper is to address "knowledge assessment" on "Foresight knowledge", we will first give an overview of what foresight actually is, before entering into the core issue of the paper - that is, what "knowledge assessment" addresses and where it could intervene in the framework of a Foresight-exercise. It may thereby also clarify the relevance of knowledge assessment beyond the context of foresight knowledge itself; although it will be seen that "foresight" is a particular case for which "knowledge assessment" is required. The first part of the paper is devoted to the deliberation process in the policy context and especially identifies the normative dimensions of such a process and its consequences for knowledge generation. The second part will enter into the issue of knowledge assessment of foresight knowledge. In both parts foresight knowledge is illustrated by reference to issues of sustainable development.
\end{abstract}

1 The views expressed here are those of the author and may not in any circumstances be regarded as stating an official position of the European Commission

Please use the following format when cining this chapter:

Von Schomberg, R., 2007, in IIIP International lederation for Information Processing, Volume 233, The Information Society: Innovations, Legitimacy, Ethics and Democracy, eds. P. Goujon, Lavelle, S., Duquenoy, P., Kimppa, K., Laurent, V., (Boston: Springer), pp. $39-56$. 
Keywords: Ethics of technology, foresight, deliberative procedures, precaution, knowledge assessment

\section{Introduction}

My analysis departs from the contested assumption that contemporary ethical theories can not capture adequately the ethical and social challenges of scientific and technological development. This assumption is rooted in the argument that classical ethical theory always addresses the issue of ethical responsibility in terms of how intentional actions of individuals can be justified. Scientific and technological developments, however, have produced unintentional consequences and side consequences. These consequences are very often the results of collective decisions on the way we wish to organise our economies and society, rather than from individual actions. For a long time, it has not been sufficient to construct an ethics of science and technology on the basis of the image of a scientist who intentionally wishes to create a Frankenstein. So as a minimum we would require an ethical framework that addresses both the aspect of unintentional side consequences (rather than intentional actions) and the aspect of collective decisions (as opposed to individual decisions) with regard to complex societal systems such as the operation of our economy. We do not have such a theory at our disposal. More disturbing than the principle shortcomings of ethical theory, are the shortcomings of conventional ethical practice vis a vis technological developments.

Below I will use four developments to illustrate these shortcomings, which centre on the fact that individuals in our society can simply not be held fully accountable for their individual role within the context of scientific technological developments. I will call it the shortcomings of a theory (and practice) of individual role responsibility. From there, I will argue why we have to shift our attention to an ethics of knowledge assessment in the framework of deliberative procedures instead.

\section{Four developments that illustrate the shortcomings of individual role- responsibility}

There has occurred a proliferation of roles within which individuals define their responsibilities. First, as a consequence of the professionalisation of multiple tasks previously carried out in nontechnical or private spheres we see an enormous differentiation of new roles individuals can take in our society. Science and engineering itself provides a modest illustration as it has broadened its functional specialisations from research, development, design, and construction to include production, operation, management, and even sales engineers; and its content specialization to include biomechanical engineering, biomedical engineering, biochemical engineering, nanoengineering, and more. Stepping outside the technical fields, the unfortunate reductio ad absurdum in this trend is the role professionalization of virtually every work-related activity: janitors become maintenance professionals, friendship becomes professional grief counselling, one 
hires professional personal trainers to help one get the right exercise, etc. Although this development is primarily manifest as the quantitative proliferation of roles, it inevitably has qualitative implications. ${ }^{2}$

Second, and in parallel, the area for which an individual may be held responsible has been narrowed, as may be illustrated with an example from the sciences that could apply equally well to engineering. In the 1700 s there were natural philosophers who pursued natural science. In the 1800 s William Whewell coined the term "scientist", and initially there were simply scientists as such (separate from philosophers). This was followed by a period in which it was possible be a physicist, chemist, or biologist. Today, however, not even the term microbiologist is sufficiently descriptive of a scientific role. As a result some individual scientists may only be proficient in research they conduct on one specific microorganism, perhaps only in relation to a restricted number of biochemical processes in that microorganism. Individual scientists increasingly "know more and more about less and less," and thus can hardly foresee the consequences of their discoveries for related fields, let alone the possible applications that could result from interactions with other fields. Such an excessive differentiation of roles implies both a formal and a substantial delimitation in individual role responsibility.

Third, the number of roles that any one individual may possibly fill has dramatically increased. Synchronically, one person may well be a structural engineer (that is, a kind of civil engineer) doing research on earthquake remediation, a grant or contract administrator, a professor of engineering, a student advisor or mentor, an academic administrator (as department head or dean), an author -- not to mention a spouse, parent, church member, citizen, consumer, and more. Diachronically, the same person may alter all of these roles and/or complement them with literally hundreds of others. Moreover, the interchangeability of individuals and roles has expanded along with individual mobility, both temporally and geographically. This means, practically, that responsibility is more identified with a role than with a person, thereby complicating the responsible organization of professional tasks while significantly diminishing technical professional ethical commitments - not to mention loyalty.

Fourth, contemporary society is not only characterized by the differentiation of roles but also by the intensified institutionalization of the social-institutional spheres in which the role differentiation takes place. Science, engineering, economics, education, politics, art, religion, and more have all become so institutionally distinct that they largely determine the conditions for their own functioning. Regulation, insofar as it occurs, must increasingly take place internally within each sphere. Scientists regulate science, engineers engineering, economists the economy, and so on. As a result of this four-dimensional transformation of role differentiation space, technical roles may be said to have become increasingly less robust at the same time that opportunities for role conflict have only intensified, proliferated, and specialized, with individuals more freely floating between roles, although large role aggregates are more rigidly separated from each other than ever before in history. The result is a multifaceted undermining of that very role responsibility which has 
been the traditional basis of social order - and for which it is dubious that principle responsibility alone is able to compensate.

Although roles are increasingly central to the functioning of technoscientific society, technical responsibility - while continuing to be framed in terms of roles - is progressively weakened in the moral sense. During the last half of the 20th century in contemporary technological societies, professional roles gained such prominence that, together with their associated expectations and codes of conduct, they constitute one of the major foundations of contemporary ethical problems and dilemmas. Especially the role responsibility of executing assigned tasks from superiors has, outside of professional philosophy, become an important ethical issues of the 20th century.

As was most dramatically demonstrated in the 1962 trial of Adolf Eichmann, strict adherence to role responsibility easily leads to an almost banal immorality ${ }^{3}$. During the trial, Eichmann defended himself by appealing to his role as chief administrator of the mass execution of Jews during Word War II, pointing out that his responsibilities were limited to administrative tasks in a hierarchy in which he had to fulfill the orders and follow the instructions given to him by superiors. Although the Eichmann case is exceptionally horrifying, the kind of appeal he made is not so exceptional at all. Repeatedly individuals in technoscientific and contemporary management positions find themselves resorting to precisely this line of reasoning to justify their behaviors. The widely studied Challenger disaster of 1986, for example, may readily be interpreted as illustrating this phenomenon ${ }^{4}$.

This infamous example and its not-so-infamous parallels have not, however, led to any wholesale rejection of individual role responsibility ethics. Instead, in the first instance it is often argued that individuals must simply acknowledge more than an administrative or technical role. Discussion has therefore focused more on the ethical dilemmas and conflicts that arise when two or more roles conflict ${ }^{5}$. This has varied from an emphasis on conflicts between the roles of being the member of a family and a professional to issues of the extent to which a technical professional may in certain situations have a responsibility to become a whistleblower. Rather than leading to an examination of the ethical foundations of role responsibility itself or the contemporary role differentiation pace, the dilemmas of role responsibility have become the focus of discussion. To resolve these dilemmas within an occupational role responsibility framework has been the primary intellectual concern, rather than to challenge the ethics of role responsibility itself.

3 See, e.g., Hannah Arendt, Eichmann in Jerusalem: A Report on the Banality of Evil (New York: Viking, 1963).

4 See Diane Vaughan, The Challenger Launch Decision: Risky Technology, Culture, and Deviance at NASA (Chicago: University of Chicago Press, 1996)

5 This is far and away the most common comment on role responsibility ethics. Dorothy Emmet, for example, in "Ethical Systems and Social Structures," Internatinal Encyclopedia of the Social Sciences (New York: Macmillan Free Press, 1968), observes in passing how individuals are often called upon "to meet the demands of a number of different and perhaps conflicting roles" and cites Chester I. Barnard's The Functions of the Executive (Cambridge, MA: Harvard Univesity Press, 1938) for documentary evidence. For other examples, see Downie, Roles and Values (1971); and David Luban, ed. The Good Lawyer: Lawyers' Roles and Lawyers' Ethics (Totowa, NJ: Rowman and Allenheld, 1983). 
Still a third attempt to address role responsibility problems has involved attempts to develop an "ethics of technology" ${ }^{\prime \prime}$ or "ethics of science", as well as a variety of studies that typically build on the phrase "social aspect of" in their titles -e.g., the social aspects of engineering, the social aspects of computing, etc. ${ }^{8}$ Such fields of scholarly activity are, however, more concerned with exploring and cataloging the phenomena themselves than with the underlying social orders or the development of normative responses to the occupational responsibility problem itself.

Interdisciplinary studies of the ethics of science and technology nevertheless regularly highlight the extent to which people increasingly feel inadequate to deal will the complex moral dilemmas in which role responsibility places them. The more common phenomenon, in the face of Eichmann-like situations, is not Eichmann-like self justification, but what Austrian philosopher Gunter Anders might associate with the doubts and guilt manifested by "Hiroshima bomber pilot" Claude Eartherly. ${ }^{9}$ But was Eartherly really responsible? What about J. Robert Oppenheimer, the leader of the scientists and engineers who designed the bomb? Or what about President Harry Truman, who ordered the bomb dropped? Or President Franklin Roosevelt, who established the Manhattan Project? Or even Enrico Fermi and Albert Einstein, who wrote the 1939 letter to Roosevelt that called attention to the possibility of an atomic bomb?

The very complexity of the atomic bomb project calls into question any attempt to accept personal responsibility for the results. Yet certainly Oppenheimer and many other atomic scientists experienced some guilt, and their concerns led to the kinds of public activism illustrated by the founding of the Federation of Atomic (later American) Scientists and the creation of the Bulletin of Atomic Scientists. Anders' paradoxical critique and idealist call for expanding human powers of imagination and responsibility ${ }^{10}$ is but the more philosophical manifestation of that intensification and multiplication of moral dilemmas which has led many people to

6 See particularly Hans Jonas, The Imperative of Responsibility: In Search of an Ethics for the Technological Age, trans. Hans Jonas and David Herr (Chicago: University of Chicago Press, 1984).

7 The ethics of science has been much more institutionalized, but at the same time remained relatively internalist. See, e.g., Kristin S. Shrader-Frechette, Scientific Research Ethics (Lanham, MD: Rowman and Littlefield, 1995).

8 One prominent synthesis of such approaches has become known as the Science, Technology, and Society (STS) movement. For a good introduction to STS, see Stephen H. Cutcliffe, Ideas, Machines, and Values: An Introduction to STS Studies (Lanham, MD: Rowman and Littlefield, forthcoming); and Stephen H. Cutcliffe and Carl Mitcham, eds., Visions of STS: Contextualizing Science, Technology, and Society Studies (Albany, NY: State University of New York Press, forthcoming).

9 Claude Eartherly and Gunter Anders, Burning Conscience (New York: Monthly Review Press, 1961). In fact, Eatherly was not the pilot of the plane that dropped the Hiroshima atomic bomb on August 6, 1945. The pilot of that plane, the Enola Gay, was Paul Tibbets, and his bombardier Thomas Ferebee, neither of whom ever expressed any regret about his role. Eartherly was the piolot of a reconnaissance place that preceded the Enola Gay and gave the a go ahead. Questions have also been raised about the reality of Earthery's feelings, but he still stands as a symbol for a certain kind of response.

10 Gunter Anders, Die Antiquierheit des Menschen, 2 vols. (Munich: Beck, 1980). 
feel that various issues are at once their responsibility and/or beyond their role competencies. The familiar not-in-my-backyard (NIMBY) syndrome in response to industrial construction or waste disposal and personal refusals to limit the consumption of high pollution consumer goods such as automobiles are but two sides of the same coin.

What thus emerges from our description of this four-dimensional transformation of the technical role responsibility space and the three attempts to respond to such a transformation is the picture of a society in which there is an imbalance in the relation between the individual's responsibility for a particular and temporary role and the collective responsibility which is represented by the simultaneous fulfilment of a great number of roles for the long-term. This is illustrated by the fact that in increasing numbers of instances it is impossible, even in a hierarchically structured technical professional system to assign to any one person responsibility for solving some particular problem. Who or what role is responsible for nuclear weapons proliferation? For stratospheric ozone depletion? For global climate change? Indeed, who or what role is responsible for even such mundane problems as traffic congestion? For the malfunctioning of my computer? For the presence of unlabelled genetically modified foods in grocery stores? The chance that any one individual can be identified as responsible for the consequences of our collective actions within and between the myriad systems and subsystems of the technoscientific world has become infinite small. Instead, in most instances it is increasingly the case that some form of co-responsibility for a collective organisation and action leading to consequences (both intended and unintended) is operative. At the same time, such collective coresponsibility is difficult to grasp and elusive; it often seems as difficult to pin down as some individual, organization, or even single body that might be held accountable for scientific and engineering developments.

\section{From Individual Role Responsibility to Collective Co-responsibility}

I have described, in an admittedly summary manner but with strong empirical references, a society in which it is difficult for anyone to be held responsible for the consequences of many technoscientific actions. We rely on a theory of occupational role responsibility that is no longer in harmony with existing social reality, in response to which we commonly propose an alternative and expanded notion of role responsibility. The fact is that the consequences of a wide variety of collective actions cannot be reconstructed from the intentions of responsible individuals, and role responsibility ethics can bear only on the consequences of individually and intentionally planned actions.

Individuals assume responsibility for the consequences of their actions if and only if they can intentionally direct those actions and reasonably assess the consequences, both intended and unintended. (Unintended consequences may on some occasions be effectively covered by insurance, as with automobile insurance.) But the consequences of scientific discovery and engineering design often escape all common or natural means of assessment.

Science and engineering exist, in the first instance, within the scientific and technological systems and, subsequently, by means of a complicated transformation 
and use, are transplanted into the system-specific logics of the economy, politics, and law. None of these system logics are traceable to the intentions of individuals, nor are the possible unintended consequences always assessable. Scientists having knowledge leading to applications which are then criticised by many in society, may rightly point out that they anticipated other applications. Engineers who design products, processes, or systems that wind up actually being used in a variety of ways (guns that kill people as well as protect them, for example) make the same argument. Scientists and engineers may even claim that the possible applications and/or uses are not part of their occupational role responsibilities as scientists or engineers.

What is clearly required is thus some transformed notion of responsibility beyond the simple multiplication of roles or the expansion of occupational role responsibility to encompass public safety, health, and welfare. Indeed, technoscientific applications can remain ethically problematic even in cases where scientists and engineers have the best possible intentions and users have no conscious intention to misuse or abuse. (Think of the example of automobile pollution.) This situation constitutes the major ethical challenge we face today.

How are we to address the problematic consequences of collective action? Technological risks are examples of special concern. The nature of many technological risks is far beyond the framework of individual responsibility. Such risks arise, as Charles Perrow has argued, as a consequence of an interaction of semiindependent systems, many of which may themselves be in part so complex as to be outside direct control ${ }^{11}$. (Think of the examples of the economy or the legal system as well as those of the various sciences and fields of engineering.) Such risks often cannot even be constrained within the dimensions of some particular time and place, which makes the identification of possible victims impossible. For such risks it is thus not even possible to take out insurance. Many of the technological risks in our society have the same status as natural catastrophes ${ }^{12}$.

In response to this problem, we would need an ethics of collective coresponsibility. The itemised inadequacies of occupational role point precisely in this direction. Such a collective ethics of co-responsibility arises from reflection on the social processes in which technological decision making is embedded. (It may even be interpreted as involving a renewed appreciation of Cicero's four-fold root of role responsibility.) That is, any new ethics must deal with the same substance as the old role responsibility ethics, namely with values and norms that restrict or delimit human action and thus enable or guide traditional decision making; but in the new ethics these values and norms will arise not simply in relation to occupational roles. Here it is appropriate to address at least four general features and requirements for the implementation of such an ethics, from which I can only elaborate the fourth feature in more detail here.

1. Public debate: To be co-responsible includes being personally responsive. It is clear that the norms of specific technical professions are insufficient because they arise from restricted perspectives. A true ethics of co-responsibility must be both

11 Charles Perrow, Normal Accidents: Living with High-Risk Technologies (New York: Basic Books, 1984). Revised edition, Princeton: Princeton University Press, 1999.

12 See, e.g., the argument of Ulrich Beck, Riskogesellschaft: Auf dem Weg in eine andere Moderne (Frankfurt am Main: Suhrkamp, 1986). 
interdisciplinary and even intercultural, in order to provide a standard of justice for evaluating and balancing conflicting occupational role responsibilities. If we fail to provide such an ethics, we inevitably continue to aggravate the clash of cultures and unarticulated hostile responses to particular (globalised) technologies.

According to my view, an ethics of collective co-responsibility is expressed at the level of free (international) public debate in which all should participate. It is unethical and even unreasonable to make any one individual responsible for the consequences and/or (adverse) side effects of our collective (especially technological) actions. It is, however, ethical and reasonable to require individual participation in public debates (subject, of course, to the particular situation), or at least make this the default position for which persons must give reasons for being excused from such a duty. Upon everyone's shoulders rests a particular moral obligation to engage in the collective debate that shapes the context for collective decision making. It is not just engineers who do social experimentation; in some sense all human beings are engineers insofar as they are caught up in and committed to the modern project.

If we trace, for instance, the history of environmental challenges, we see that many issues which depend on the involvement of personally responsible professionals were first identified and articulated within the public sphere. Public deliberation does not primarily aim at creating of itself a reasonable consensus, but serves, among others, the function of presenting different relevant issues to the more or less autonomous systems and subsystems of society - that is, to politics, law, science, etc. The typically independent discourses of politics, law, science, etc. are called upon to respond to issues raised in public debate. An appropriate response by the appropriate subsystem to publicly identified and articulated issues constitutes a successful socioethical response. Conversely, responsible representatives of the subsystems are drivers for new debates, when they publicize particular aspects of an issue that cannot be fruitfully resolved within the limits of some specialized discourse. The continuous interaction between the autonomous subsystem discourses and a critically aware public provides an antidote for frozen societal contradictions between opposing interests, stakeholders, or cultural prejudices.

2. Technology assessment: To be collectively co-responsible involves developing transpersonal assessment mechanisms. Although the institution of the public realm and interactions with the professionalized subsystems makes it possible for individuals to be co-responsive, these deliberations are in many cases insufficiently specific for resolving the challenges with which technological development confront us -- that is, they do not always lead to the implementation of sufficiently robust national or international policies. Therefore all kinds of specific deliberative procedures - for instance deliberative technology assessment procedures - must be established to complement general public debate and to provide an interface between a particular subsystem and the political decision-making process. The widely discussed consensus conferences are one example of an interface between science and politics ${ }^{13}$. (Of course, the question remains here whether these types of interface are adequate ones).

13 See I. Mayer, Debating Technologies: A Methodological Contribution to the Design and Evaluation of Participatory Policy Analysis (Tilburg, Netherlands, Tilburg University Press, 
The implementation of ethics codes by corporations also constitutes an interface between the economic sector, science, and stakeholder interest groups, while national ethics committees are often meant as intermediaries between the legal and political system. Experiments with such boundary activities or associations have been, depending on the case, more or less successful. They represent important experiments for enabling citizens to act as co-responsible agents in the context of technological decision making. Yet the absence of adequately deliberative forums is certainly one reason why we are not yet able to democratically plan our technological developments.

3. Constitutional change: Collective co-responsibility may eventually entail constitutional or structural political change. The initiation of specifically new forms of public debate and the development of transpersonal science and technology assessment processes may eventually require constitutional adjustment. Indeed, the adaptation of specific deliberative principles in our constitutions must not be ruled out. Consider, for instance, the possible implementation of the precautionary principle, which is inscribed in the European Treaty and now also guides important international environmental deliberations (the Kyoto Protocol on Climate Change, the Biosafety Protocol, etc.). This principle lowers the threshold at which governments may take action to restrict scientific or technological innovation. It does not have to be shown with certainty that bad consequences will follow; it is sufficient if there is an absence of scientific certainty in cases where there is some indication of possible serious or irreversible harm to human health or the environment. The very implementation of such a principle requires new and badly needed intermediate deliberative science-policy structures. It imposes an obligation to continue to seek scientific evidence and enables also an ongoing interaction with the public on the acceptability of the plausible adverse effects and the chosen level of protection. The principle also requires companies to become more proactive and necessarily shapes their technoscientific research programs in specific ways.

4. Foresight and Knowledge assessment. The issue of unintentional consequences can be traced back among others to the (principle) limited capacity of the scientific system to know in advance the consequences of scientific discoveries and technological actions. Virtually all complex technological innovations from which our societies do benefit, are surrounded by scientific uncertainties and several degrees of ignorance. Instead of addressing the ethics of technology, it could therefore be more appropriate to address the "ethics" of knowledge transfer between our societal spheres such as the knowledge transfer between science and policy. As the "quality of the knowledge" will, by and large, determine our relative successes in using this knowledge in the context of all kinds of possible applications. At the same time, we do constantly need a form of foresight (as predictions about our future have been shown to be enormously imperfect) in which we evaluate the quality of our knowledge base and try to identify at an early stage societal problems and new

1997); and I. Mayer and J. Geurts, "Consensus Conferences as Participatory Policy Analysis: A Methodological Contribution to the Social Management of Technology," in P. Wheale, Rene von Schomberg, and P. Glasner, eds., The Social Management of Genetic Engineering (Aldershot, England: Ashgate, 1998), pp. 279-301. 
knowledge needs. In the next section I will analyse the normative elements of foresight knowledge assessment ${ }^{14}$.

\section{Foresight and Knowledge assessment}

The challenges that science related to public policy face today, have to do with the increasing recognition of the complexity of socio-environmental problems, requiring (ideally) extended engagement of relevant societal sectors for their framing, assessment, monitoring, and an extended deliberation process.

Foresight aims at providing visions of the future to explore effective strategic policy. Envisioning is inherent to any technological, environmental and social activity. It is explicitly or implicitly in assessment methodologies, policy documents or political discourse. Foresight is naturally bound by uncertainty and ignorance, multiple values, requiring a robust knowledge base made of different types of knowledge as the background and the justification of the exercises' outcomes.

The threats and opportunities of biotech have often been explored on the basis of the experience with nuclear technology. Nanotechnology is increasingly being compared on the basis of experience with biotechnology (see for example Grove White et al, 2004). Analogies or counterfactuals, do not allow for predictions but produce prospective plausibility claims, which, however, do have sufficient power to allow us to explore the future on the basis of consolidated knowledge from known areas. Conflicting plausibility claims articulate and make us aware of uncertain knowledge whereby equally plausible claims are based on alternative sources of knowledge (most often from different scientific disciplines). However, these plausibility claims mutually lack any falsifying power (see Von Schomberg, 2003). They either lose substance or become more persuasive, once empirical research supports particular paradigms resulting from those plausibility claims. For instance, the argument (an analogy) of a "greenhouse effect" set the plausibility of the occurrence of global warming: an analogy that has been strengthened by actual observed temperature rises over the last decade, although the empirical basis in itself would not be sufficient to prove the thesis of the greenhouse effect. Foresight knowledge distinguishes itself from "normal" scientific knowledge, in the sense of Kuhn's normal science, and shares many aspects (although not identical) with what Ravetz \& Funtowicz (1990) have called post-normal science:

Foresight knowledge can be distinguished from knowledge produced by normal science since it has the following features:

1. Foresight knowledge is non-verifiable in nature since it does not give a representation of an empirical reality. It can, therefore, also not be related to the normal use for the "predictability" of events. The quality of foresight knowledge is discussed in terms of its plausibility rather than in terms of the accuracy of the predictability of certain events. Foresight exercises are therefore often characterised as "explorative" in nature and not meant to produce predictions;

14 For an extensive analysis see: Von Schomberg et al (2005), Deliberating Foresight Knowledge for Policy and Foresight Knowledge Assessment, A working document from the European Commission Services, Directorate General for Research, Brussels. 
2. Foresight knowledge has a high degree of uncertainty and complexity whereby uncertainties exist concerning particular causal relationships and their relevance for the issue of concern;

3. Foresight knowledge thematises a usually coherent vision whereby relevant knowledge includes an anticipation of "the unknown";

4. Foresight knowledge has an action-oriented perspective (identification of threats/challenges/opportunities and the relevance of knowledge for a particular issue) whereby normal scientific knowledge lacks such an orientation;

5. Foresight knowledge shares a typical hermeneutic dimension of the social sciences and the humanities, whereby the available knowledge is subject to continuous interpretation (e.g. visions of "the future" or what can account for a "future" are typical examples of such an hermeneutic dimension);

6. Foresight knowledge is more than future-oriented research: it combines normative targets with socio-economic feasibility and scientific plausibility;

7. Foresight knowledge is by definition multi-disciplinary in nature and very often combines the insights of social and natural sciences.

Foresight knowledge can be understood as a form of "strategic knowledge" necessary for agenda setting, opinion formation and vision development and problem-solving. In the case of underpinning the objective of sustainable development, Grünwald ${ }^{15} 16$ has captured the characteristics of "strategic knowledge for sustainable development", in which many of the above mentioned general aspects of foresight knowledge reappear, in the following three statements:

- strategic knowledge, as a scientific contribution to sustainable development, consists of targeted and context-sensitive combinations of explanatory knowledge about phenomena observed, of orientation knowledge evaluative judgements, and of actionguiding knowledge with regard to strategic decisions (compare the aspects 4,5 and 7 above);

- this strategic knowledge is necessarily provisional and incomplete in its descriptive aspects, as well as dependent on changing societal normative concepts in its evaluative aspects (compare aspects 2 and 6 above);

- dealing with strategic knowledge of this sort in societal fields of application leads to a great need for reflection on the premises and uncertainties of knowledge itself. Reflexivity and the learning processes building upon it become decisive features in providing strategic knowledge for sustainable development (relates to aspects 1 and 3 above).

\section{Foresight and Deliberation}

Foresight activities should be adapted to processes of deliberative democracy of modern western societies. Deliberation goes obviously beyond the meaning of simple discussions concerning a particular subject matter, and in its broadest

15 Grunwald, A. (2004) 'Strategic Knowledge for Sustainable Development: The Need for Reflexivity and Learning at the Interface between Science and Society', International Journal of Foresight and Innovation Policy, 1.1-2: 150-67 
meaning can be understood as "free and public reasoning among equals" (Cohen, $1994)^{16}$.

Deliberation takes place at the interface of different spheres, as we will see for example when we deliberate on the basis of foresight knowledge. In this section, I especially explore the deliberations that take place at the policy making level and at the science-policy interface.

The deliberation levels that relate to particular spheres, such as "politics", "science" or "policy", can be characterised by specific normative boundaries. The specific outcomes from each deliberation level can be fed into other levels of deliberation, which are constrained by yet another set of distinct normative boundaries. Most often these boundaries are not simple consensual assumptions, justly shared by the actors involved, but may be fundamental policy or constitutional principles which are the result of longer learning processes and which have to be shared in order to achieve particular quality standards of policies and decisions. For instance, deliberation on risks and safety under product authorisation procedures within the European Union are guided by the policy objective, which is enshrined in the EU treaty, to aim at a high level of protection of the European citizen.

Below, I will outline the normative boundaries of the different levels of deliberation (see table 1) within which foresight activities are invoked, implemented or applied. It should be noted that the different levels of deliberation do neither represent a hierarchy nor necessarily a chronological sequence, as deliberation levels mutually inform and refer to each other, deliberation at each particular level, can spark new deliberation at other levels.

We work here on the basis of examples of a most advanced form of embedded foresight integrated in a wider policy context. What follows is an ideal-type of description of all relevant deliberation levels in relation to the use of foresight knowledge (although there are striking similarities with the usage of (scientific) knowledge in policy as such). Theorists of deliberative democracy work on the clarification of particular levels of deliberation within particular spheres of society. Neblo $^{17}$ (2004) describes levels of public deliberation in terms of "deliberative breakdown". Fisher $1^{18}(2003)$ and Dryzek ${ }^{19}$ (1990) describe procedures of discursive politics. Grin et al. (2004) ${ }^{20}$ defines particular deliberations as practices of "reflexive design". We will here elaborate the levels relevant for deliberating foresight knowledge for public policy.

16 Cohen, J(2004). Procedure and Substance in Deliberative Democracy in S.Benhabib (ed) Democracy and Difference. Princeton, New Jersey, Princeton University Press.

17 Neblo, M.A. (2004). Thinking through Democracy: Deliberative Politics in Theory \& Practice, Paper presented at the Conference on "Empirical Approaches to Deliberative Politics" European University Institute, Firenze, 21-22 May 2004

18 Fischer, F. (2003). Reframing Public Policy. Discursive Politics and Deliberative Practices. Oxford: Oxford University Press

19 Dryzek, J.S. (1990). Discursive democracy: politics, policy, and political science, Cambridge: Cambridge University Press.

20 Grin, J., Felix, F., Bos B. and Spoelstra S. (2004). Practices for reflexive design: lessons from a Dutch programme on sustainable agriculture, Int. J. Foresight and Innovation Policy. Vol 1. Nos $1 / 2$, pp.126- 149. 
The very first level concerns a broad political deliberation, which assumes a political consensus on the need for long-term planning when it engages in foresight exercises.

At that broad political level, foresight will be understood as a form for early anticipation and identification of threats, challenges and opportunities that lie ahead of us. Foresight exercises are essentially about the identification of such threats/challenges/opportunities. It is thereby important to realise that, for instance, a Technology Foresight exercise identifies technologies or other developments that may have an important impact, rather than assessing those technologies themselves:

"The act of identification is an expression of opinion (italics: by authors of this paper) (which amounts to a form of implicit, covert assessment, the assessment of the relative importance of the technologies identified must necessarily follow their identification" (Loveridge, 2004: p.9).

Those "opinions" are unavoidably normative in nature, and do not relate directly to the assessment of the technology but rather to the assessment of their potential with regards to particular perceived or actual threats/challenges and opportunities. A proper foresight exercise should therefore make these dimensions explicit in order to feed a deliberation process on a sound basis before achieving final conclusions. Foresight exercises need to refer to widely shared objectives (for instance those in international treaties and constitutions) such as the objective of sustainable development with its recognised three pillars (social, economic and environmental) in order to embed the broad political context. Foresight exercises can also be built on more controversial assumptions, yet those exercises may have a function of stimulating and informing a broader public debate rather than aiming at particular policies and or actions. Foresight exercises can be invoked at this political level of deliberation.

In a second level, one can identify deliberation at the policy level which immediately builds upon outcomes of political deliberation. It will need to map and identify those challenges/ threats and opportunities which are (in)consistent with more particular shared objectives, such as a high level of protection of consumers and the environment, sustainable growth and economic competitiveness. At this level a policy framework needs to be agreed upon for the implementation of foresight in a broad sense, at least by identifying institutions and actors which will take charge of foresight exercises. A number of countries have institutions, such as particular councils, committees or assessment institutes for those tasks in place. Such institutions can then plan studies which are part of the foresight exercise and can include activities such as (sustainability) impact studies, cost-benefit analysis, SWOT analysis, scenario studies etc. These studies should outline scenario's, challenges and threats and verify its consistency with relevant drivers.

A third deliberation level, the science/policy interface, is of particular interest since it qualifies the input of a diverse range of knowledge inputs, e.g. those of the scientific community, stakeholders and possibly the public at large by applying foresight (scenario workshops, foresight techniques/studies/panels etc).

At the science/policy interface, the state of affairs in science needs to be identified in relation to the identified relevant threats/challenges and opportunities. A particular task lies in the qualification of the available information by formulating statements on the available information in terms of sufficiency and adequacy - a 
preliminary form of Knowledge assessment. The identification of knowledge gaps is a particular task to sort out the state of affairs in science, possibly leading to later recommendations for further scientific studies to close those gaps. Also, depending on the timelines during which those decisions should be made, particular decision procedures for situations under conditions of uncertainty need to be taken into account. When communicating the results of the science/policy interface to the policy and political level, the proper handling of uncertainty has to be taken care of, and failure to do so have often lead to disqualifications of the used scientific knowledge at political level and in public debate. With uncertain knowledge, particular assumptions must be made as to whether particular consequences pose in fact a threat to us or not. For example: do we see 1,2 or three degrees temperature rise as unacceptable consequence in terms of climate change? Do we think a 3 percent increase on public and private investments in science and technology by 2010 would make our economy sufficiently competitive? These assumptions represent "transformable norms", as their acceptability changes in the light of ongoing new scientific findings. For instance, an initially assumed acceptable normative target of a global two degrees temperature rise may turn unacceptable when new scientific findings indicate to more serious consequences than previously thought. New knowledge about these issues leads to continuous reframing, making Foresight and monitoring practices necessary partners. 


\begin{tabular}{|c|c|c|c|}
\hline $\begin{array}{l}\text { Normative } \\
\text { boundary of } \\
\text { deliberation level }\end{array}$ & $\begin{array}{l}\text { Type of } \\
\text { operational } \\
\text { normative } \\
\text { rationale }\end{array}$ & $\begin{array}{l}\text { Factors/normative } \\
\text { considerations to be } \\
\text { taken into account }\end{array}$ & $\begin{array}{l}\text { Normative } \\
\text { decision modi }\end{array}$ \\
\hline $\begin{array}{l}\text { Broad political } \\
\text { debate }\end{array}$ & $\begin{array}{l}\text { Political } \\
\text { consensus on } \\
\text { long term } \\
\text { planning }\end{array}$ & $\begin{array}{l}\text { Invocation of Foresight } \\
\text { Threats/challenges } \\
\text { /opportunities; } \\
\text { normative reference } \\
\text { points: } \\
\text { Three pillars of } \\
\text { Sustainable } \\
\text { development/ } \\
\text { Lisbon/Barcelona }\end{array}$ & $\begin{array}{l}\text { Early } \\
\text { anticipation/ } \\
\text { identification }\end{array}$ \\
\hline $\begin{array}{l}\text { Choice of } \\
\text { Sustainable } \\
\text { Development } \\
\text { targets } \\
\text { challenges }\end{array}$ & 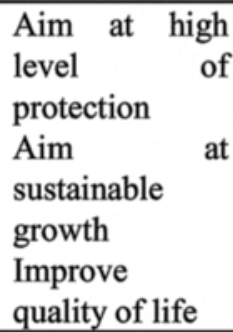 & $\begin{array}{l}\text { High Level of } \\
\text { protection } \\
\text { Sustainable growth, } \\
\text { competitiveness }\end{array}$ & $\begin{array}{l}\text { Defining/ } \\
\text { Mapping } \\
\text { Threats and } \\
\text { Challenges }\end{array}$ \\
\hline Political/societal & $\begin{array}{l}\text { Choice of } \\
\text { policy } \\
\text { framework }\end{array}$ & $\begin{array}{l}\text { Implementation of } \\
\text { foresight }\end{array}$ & $\begin{array}{l}\text { Allocation of } \\
\text { tasks to Foresight } \\
\text { institutions/invol } \\
\text { vement of parties }\end{array}$ \\
\hline $\begin{array}{l}\text { Broad policy } \\
\text { debate }\end{array}$ & $\begin{array}{l}\text { Cost/Benefit } \\
\text { analysis } \\
\text { impact analysis }\end{array}$ & $\begin{array}{l}\text { Health/environment } \\
\text { takes precedence over } \\
\text { economic } \\
\text { considerations }\end{array}$ & $\begin{array}{l}\text { Priority } \\
\text { setting/selection } \\
\text { e.g. minimalising } \\
\text { costs, } \\
\text { maxamilising } \\
\text { benefits, priority } \\
\text { to health etc }\end{array}$ \\
\hline Type of measures & $\begin{array}{l}\text { Enabling } \\
\text { Monitoring } \\
\text { practice }\end{array}$ & $\begin{array}{l}\text { Proportionality } \\
\text { requirement }\end{array}$ & $\begin{array}{l}\text { Measures to } \\
\text { enable } \\
\text { Monitoring } \\
\text { practice, } \\
\text { Learning practice } \\
\text { development of } \\
\text { indicators/bench } \\
\text { marking }\end{array}$ \\
\hline
\end{tabular}




\begin{tabular}{|c|c|c|c|}
\hline $\begin{array}{l}\text { Normative } \\
\text { qualification of the } \\
\text { scientific debate }\end{array}$ & $\begin{array}{l}\text { Identification } \\
\text { of state of } \\
\text { affairs in } \\
\text { science/normati } \\
\text { ve qualification } \\
\text { of knowledge } \\
\text { Identification } \\
\text { of knowledge } \\
\text { gaps }\end{array}$ & $\begin{array}{l}\text { Particular } \\
\text { threats/challenges/ } \\
\text { opportunities } \\
\text { Application } \\
\text { foresight }\end{array}$ & $\begin{array}{l}\text { Normative } \\
\text { qualification of } \\
\text { available } \\
\text { information. } \\
\text { Relating the } \\
\text { quality } \\
\text { available } \\
\text { information to } \\
\text { Importance of } \\
\text { challenges etc } \\
\end{array}$ \\
\hline $\begin{array}{l}\text { Normative } \\
\text { approach to } \\
\text { dealing with } \\
\text { threats/challenges/ } \\
\text { opportunities }\end{array}$ & $\begin{array}{l}\text { Identification } \\
\text { of } \\
\text { transformable } \\
\text { standards, } 3 \\
\text { percent target, } \\
\text { etc scientific } \\
\text { and } \\
\text { technological } \\
\text { options }\end{array}$ & $\begin{array}{l}\text { (Undefined) } \\
\text { normative standards } \\
\text { for acceptability, } \\
\text { safety etc of } \\
\text { products/processes }\end{array}$ & $\begin{array}{l}\text { Choice of } \\
\text { transformable } \\
\text { standards: growth } \\
\text { rates, } \\
\text { sustainability } \\
\text { targets, for } \\
\text { example:reductio } \\
n \text { of biodiversity, } \\
\text { acceptable levels } \\
\text { of temperature } \\
\text { rise, levels of } \\
\text { use of } \\
\text { renewables etc }\end{array}$ \\
\hline
\end{tabular}

Table 1: Deliberation levels involving the progressive invocation, application and implementation of foresight with its normative boundaries

\section{References}

Achen Thomas (2004), "The normative dimensions of the precautionary principle and its relation to science and risk management decisions", in: Microscopic Modification and Big Politics Linkoeping Studies in Arts and Science, Vadstena, Sweden.

Von Schonberg René (2002), "The objective of Sustainability. Are we coming closer?", Working paper number 1 of the Science and Technology Foresight, Unit of DG Research, European Commission, http://www.cordis.lu/foresight/working.htm

Von Schomberg and Baynes (Eds) (2002), "The Erosion of Valuespheres: The Ways in which Society Copes with Scientific, Moral and Ethical Uncertainty State" in: Discourse and Democracy. Essays on Habermas' Between Fact and Norms, State University of New York Press, Albany. 
Von Schonberg René (2000), "The Ethics of Scientists and Engineers: The empirical turn in the philosophy of technology", in Peter Kroes and Anthonie Meijers (ed.), Research in philosophy and technology, vol. 20, JAI Press, Amsterdam [etc.] pp. 167-189

Von Schonberg René (2000), “Agricultural Biotechnology in the Trade-Environment Interface: Counterbalancing Adverse Effects of Globalisation", in D. Barben and G. Abels (eds.), Biotechnologie - Globalisierung-Demokratie, Berlin: Edition Sigma, pp. 111-131

Von Schonberg René (1996), Offentlichkeit als Kontrolle technologischer Innovation", in: Analyse und Kritik, August 1997, pp. 108-125 